\title{
DOROTHY Mass Foot Measurement Campaign
}

\author{
Aleš JURCA*, Tomaž KOLŠEK, Tina VIDIĆ \\ UCS d.o.o., Vrhnika, Slovenia
}

\begin{abstract}
Mass foot measurement campaign, which took place in 11 European countries, was a part of DOROTHY, an EU funded RTD program, aimed at transforming the shoe industry and its related business model to strengthen Europe's ability to compete in terms of high added value for the customer. Scanning was performed by companies Alpina, Decathlon and Fidas and by institutes ITIA and LMS. 10676 feet were scanned with infoot $3 d$ laser scanners. All collected data were checked, the corrupted scans were excluded from further analysis. Most significant foot dimensions were extracted by UCS Grafomat software, stored in a database and finally analyzed with statistical analysis tools. Foot analysis was performed separately for children, adult male and adult female subjects. Feet were classified in different classes for the most important feet measurements. With cluster analysis the population was divided into three clusters: every foot was appointed to the cluster with the closest cluster center of four measurements.

Dorothy foot database is probably the largest European 3D foot scan database. Conclusions of the feet analysis reveal new findings of the human foot dimensions. The most surprising conclusions of the analysis are high foot width and foot height dispersions, which show the need for various widths of the same shoe model and size. Feet analysis shows low foot width-height correlation, which means that a wide foot is not necessarily a high foot. Measurement campaign and mass data analysis should provide important data for producing mass customized shoes, to fully personalize the shoe to individual customer's desires and feet dimensions and also to create better fit of standard mass produced shoes. Result of the analysis should help shoe manufacturers to better fit their production to different customer needs and requirements.
\end{abstract}

Keywords: 3D foot measurements, foot database, foot dimensions analysis

\section{Introduction}

Foot length was object of many studies (Levy, Ashizawa, Peker, Cheng...). Although human beings are considered to be bilaterally symmetrical, there is an asymmetry in the length of the feet [1]. Commonly used shoe sizing systems are predominantly in the length dimension [2], however some other foot dimensions, together with individual and racial differences have to be precisely known for optimal manufacturing of shoe lasts [3]. Even though it is well known that fit or product compatibility is necessary for a person to experience comfort, safety and satisfaction during use, form has dominated the design and development of footwear over the last few decades [4].

There is rising awareness in last decades that size and fit are much more important for men and women than fashion, price and quantity. Rising necessity for 3D knowledge about the human feet has resulted in launching many of national measurement projects. The aim was to acquire information about feet in order to design ergonomic footwear [5].

Traditionally many women's shoes have been made using a small version of a men's last with all dimensions proportionally scaled according to foot length, which is an inappropriate model for a women's shoe last and could lead to improper shoe fit in women, since women feet differ in a number of shape characteristics. While males have significantly longer and broader feet than females, woman's foot has a higher arch, a shallower first toe, a smaller ball of foot circumference, a shorter ankle length, a shorter length of the outside ball of foot, and a smaller instep circumference. For this reason female footwear shouldn't be simply scaled-down isometric versions of male footwear but it should reflect all those differences in order to provide the perfect fit [6]. The foot-shoe fit depends on many factors. The size variations of the feet are always an excuse to avoid quatifying the fit between shoes and feet. The traditional criteria were to compare the length of the foot. Thus, subjective ratings of fit may be evaluated, as performed by Witana [7], although on a small sample of people.

The massive acquisition of foot shape data is today possible by using fast optical scanning devices. Such data may be collected either through sales or systematic foot measurement, as described by Anil [8].

*ales.jurca@ucstech.eu; +386-1-750-7132; www.ucstech.eu 
Mass data acquisition campaign, which took place in 11 European countries, is a part of EU project Dorothy. Since footwear sector is of great importance for industrial production and employment in a number of European countries, product quality and added value must be improved significantly, in order to compete with emerging economies. Result of analysis should help shoe manufacturers to best fit their production to different customer needs and requirements around the world and thus contribute to one of the Dorothy's objective: Design tools for the customer driven shoes.

\section{Method}

\subsection{Scanning campaign}

During the scanning campaign 5338 subjects scanned both feet with Infoot USB High Type optical foot scanners. Scanning was performed by companies LMS, Fidas, Alpina, Decathlon and ITIA, who provided necessary data for feet analysis. Left and right feet were stored as separate files of the same person in a FBD (Foot Binary Data) format, which was later converted to CSV (ASCIl format containing $3 \mathrm{D}$ coordinates of points on the foot surface). Before scanning each subject was assigned a code, and was asked to reveal information about age, gender, EU shoe size, weight and height. This information was automatically stored in a database file which was enclosed to foot scans. All scans were sent to UCS, where they were checked for validity and, when necessary, edited. 446 scans which were corrupted (due to different reasons - see Figure 1), and couldn't be properly edited, were removed from further analysis.

\subsection{Relevant foot measurements extraction}

In order to ensure comparative results, 3D foot scans were positioned and oriented in the Cartesian coordinate system according to two points: $A$ and $B$; where point $A$ is defined at $10 \%$ of foot length along $X$ axis, at the middle of utmost points on $Y$ axis; and point $B$ is defined at $66 \%$ of foot length along $X$ axis, at the $60 \%$ of distance between utmost points on $Y$ axis. Both points are detected on up to $10 \mathrm{~mm}$ of foot height on $Z$ axis (see Figure 1).

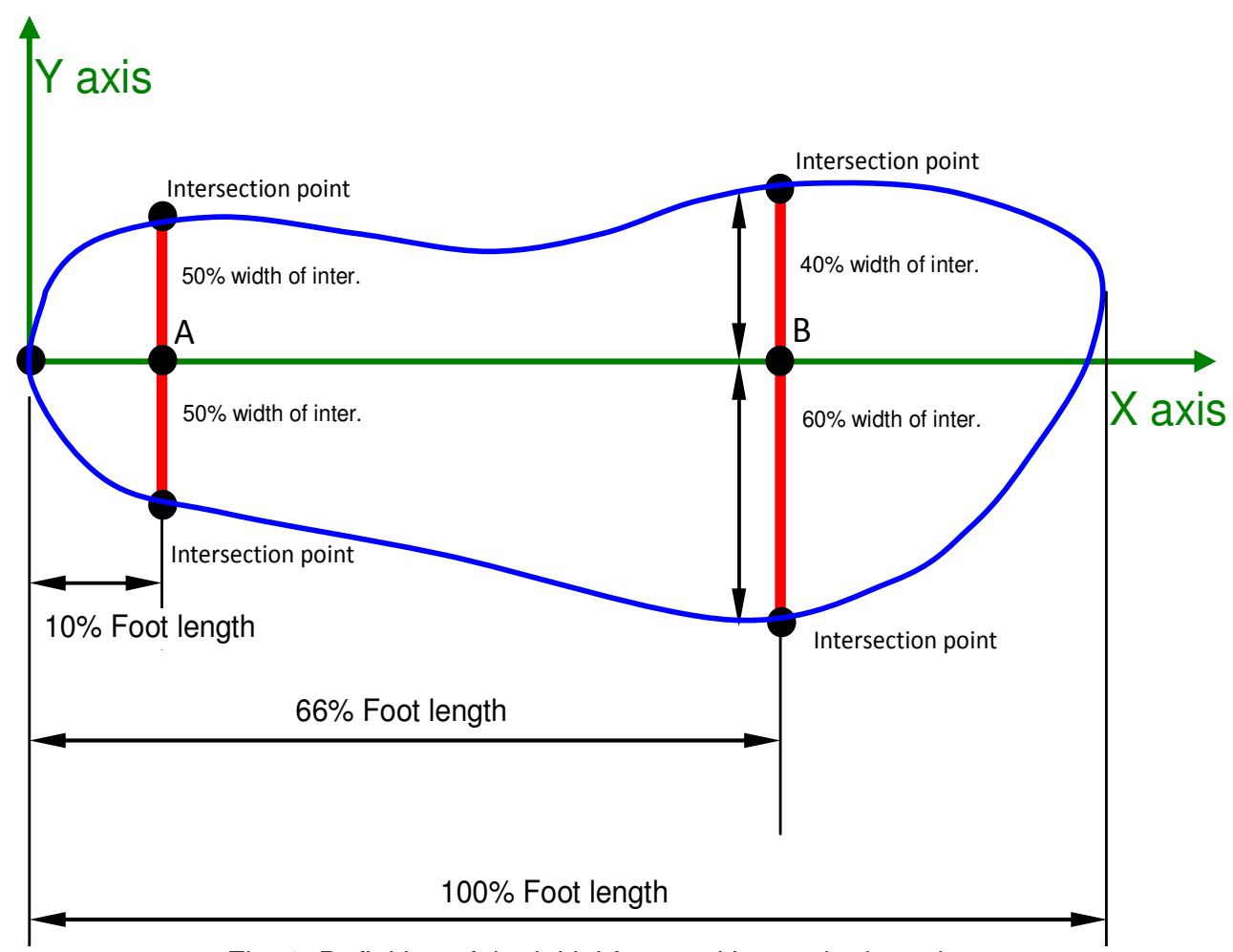

Fig. 1. Definition of the initial foot position and orientation 
UCS proprietary software GRAFOMAT was used to extract the following relevant foot measurements: foot length, foot width, foot height, metatarsal girth, long heel girth and heel width, which are explained in the following paragraphs.

\subsubsection{Foot length}

The Foot Length is the distance along $X$ axis, measured from the minimum $x$-point within the heel area, to the maximum $x$-point within the toes area (the later may be either first or second toe), see Figure 2.

\subsubsection{Foot width}

The Foot Width is determined as the distance in y-direction between the two points: Inner contour maximum y-point (ICMP) and outer contour minimum y-point (OCMP). ICMP is detected in the range $65 \% \ldots 80 \%$ foot length, whereas OCMP is detected in the range $50 \% \ldots 80 \%$ length, see Figure 2 . This methodology eliminates questionable local maximums related to flat feet and first toe pointing outwards.

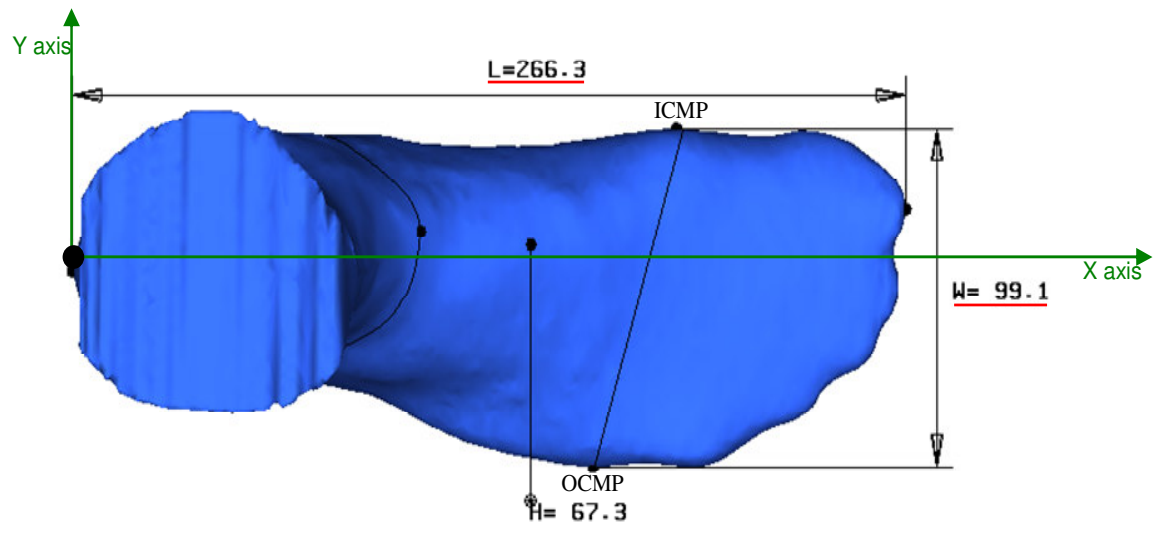

Fig. 2. An example of Foot Length (L) and Foot Width (W) measurement

\subsubsection{Foot height}

The Foot Height is the distance from xy-plane to maximum z-point on the side foot silhouette, whose $x$-distance from the origin is $55 \%$ of foot length, see Figure 3 .

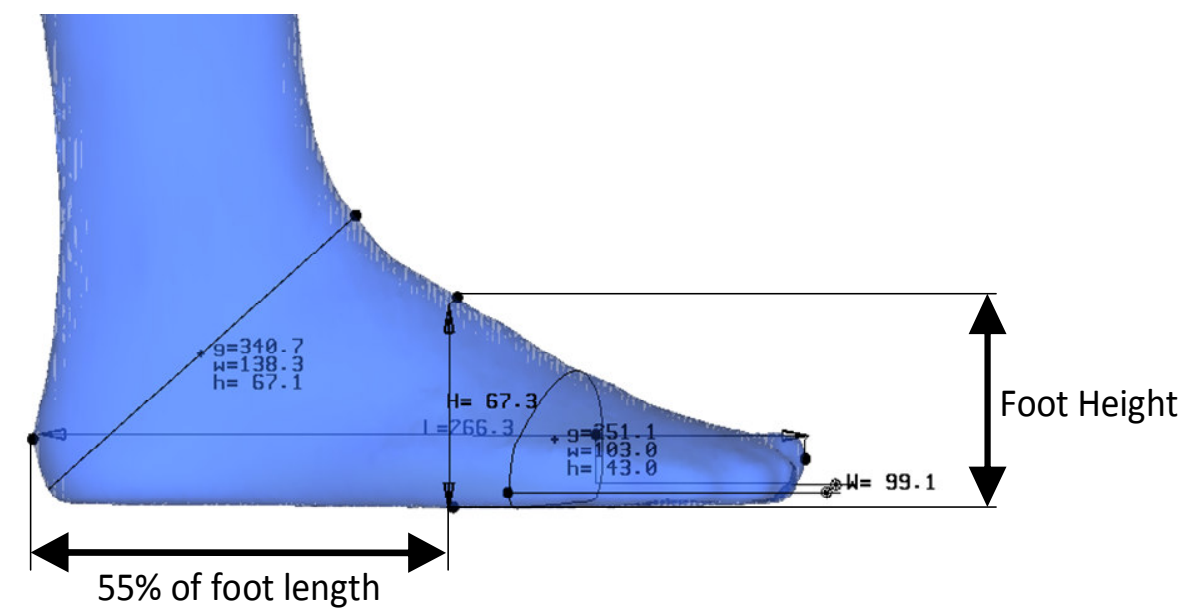

Fig. 3. An example of Foot Height measurement

\subsubsection{Metatarsal girth}

The Metatarsal Girth is obtained by calculating the intersection of the plane and the triangulated foot surface. The plane passes through point ( $x=69 \%$ of foot length, $y=0, z=0)$ and is rotated about $z$-axis by 16 degrees with respect to $y-z$ plane. The values were empirically determined based on a large number of tests. The result is the girth passing over first and fifth metatarsal head (the 2 extreme bones) as seen on Figure 4. According to our experience we estimate, that the results of measurement using other methods of determination of metatarsal intersection position, including manual positioning, are not more reliable. 


\subsubsection{Long heel girth}

The Long Heel Girth is obtained by calculating the intersection of the plane with foot triangulated surface. The plane is inclined from $x$-y plane by such an amount, that it passes through the point on the foot side silhouette, which is closest to the $(0,0,0)$ point, as seen on Figure 4.
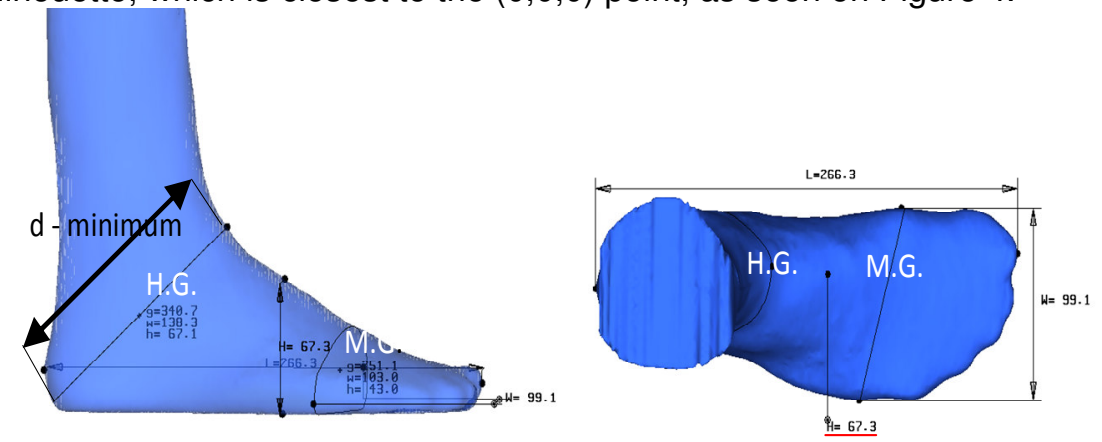

Fig. 4. example of Metatarsal Girth (M.G.) and Long Heel Girth (H.G.) measurement

\subsubsection{Heel width}

The Heel Width is determined as the distance in $y$-direction between the two utmost points - A and B, where both points are defined at exactly $15 \%$ of foot length in $x$-direction and up to $30 \mathrm{~mm}$ high in $z$-direction. By limiting the distance in z-direction, we exclude ankles and calf from measurement. See Figure 5.

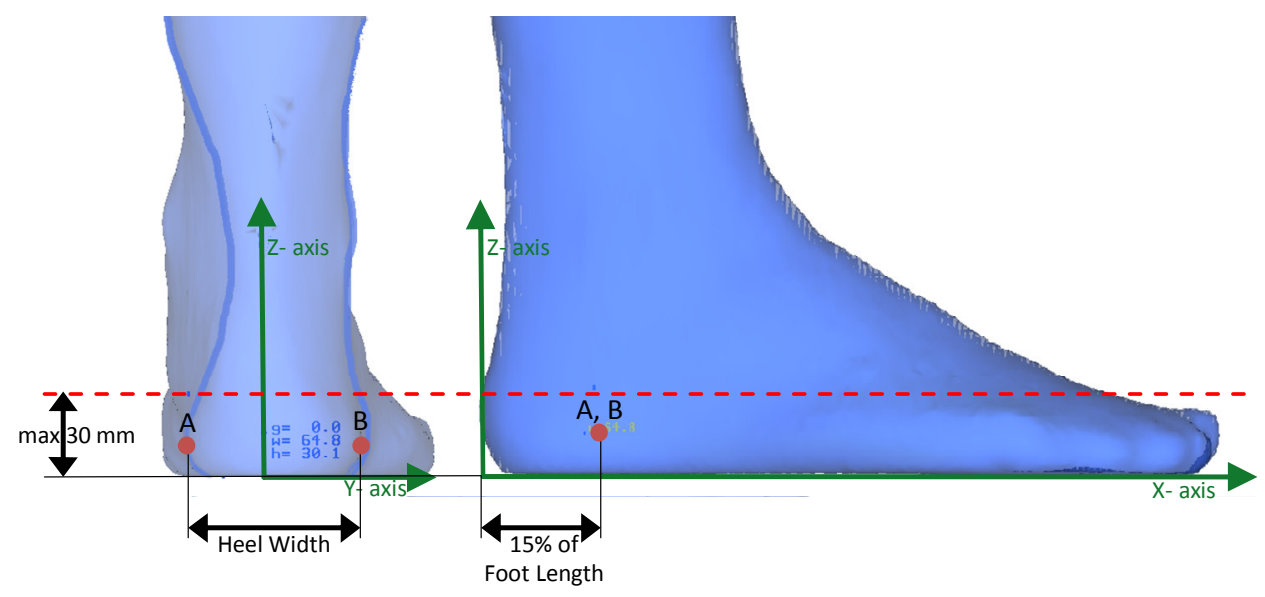

Fig. 5. An example of Heel Width measurement

\subsection{Statistical analysis}

A number of statistical tests were performed with variables: gender, age, EU Shoe Size, relevant foot characteristics in order to extract relevant information about human feet in different European countries and in general. Based on our experience, the following parts of statistical analysis may be of interest to the potential shoe last maker: descriptives (Mean, Median, Variance, Standard deviation, Skewness, Curtosis) with tests of normality, frequencies with histograms, correlations and regressions with curve fit.

Where possible, analysis was segmented: by age (children $<=15$ years and adult $=>16$ years), by gender (adults: male, female) and geographical region (11 European countries).

Second step of analysis was to determine correlation between different variables. We expected that foot dimensions are in a mutual correlation; we also expected strong significance of correlation between age and foot dimensions for children population. When correlation between relevant feet characteristic was shown as significant, regression calculation was used to show dependence between foot length and other relevant foot dimensions. 


\section{Results}

Geographical distribution of subjects is displayed in Fig. 6. During data preparation 370 feet scans (cca. $3,5 \%$ ) were removed from further analysis due to different reasons.
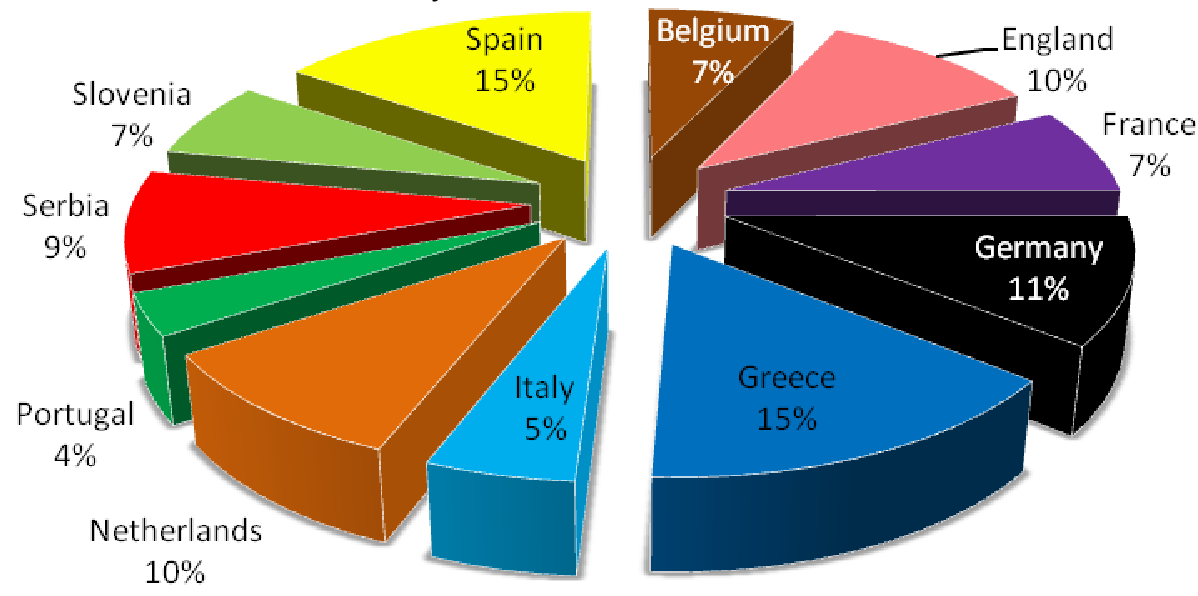

Fig. 6. An example of Heel Width measurement

Statistical analysis was conducted on 10.230 feet scans, of which 1.010 were children (age $<=15$ years), 5.596 were adult male (age =>16) and 3.624 were adult female. Distribution of cases by country for each of those three groups vary significantly (from $0,8 \%$ of all collected data) and in some cases prevents appropriate comparisons.

Foot length vs. foot width chart (Fig. 7.), foot length vs. metatarsal girth chart (Fig. 8.) and foot length vs. foot height chart (Fig. 9.) show high dispersions.
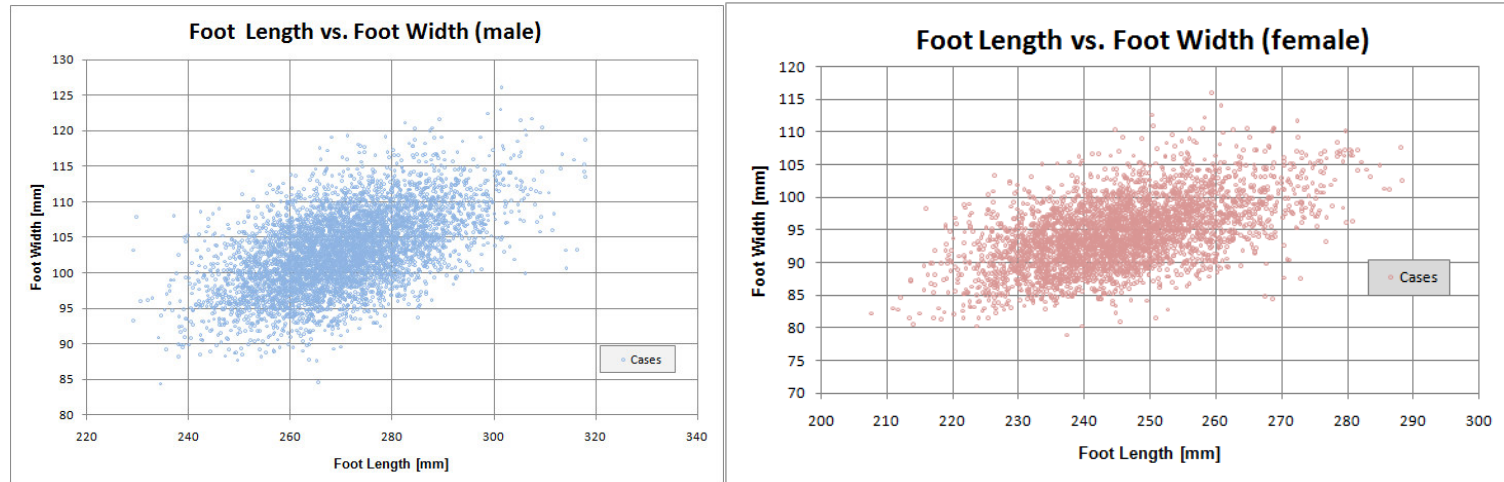

Fig. 7. Foot length vs. foot width charts
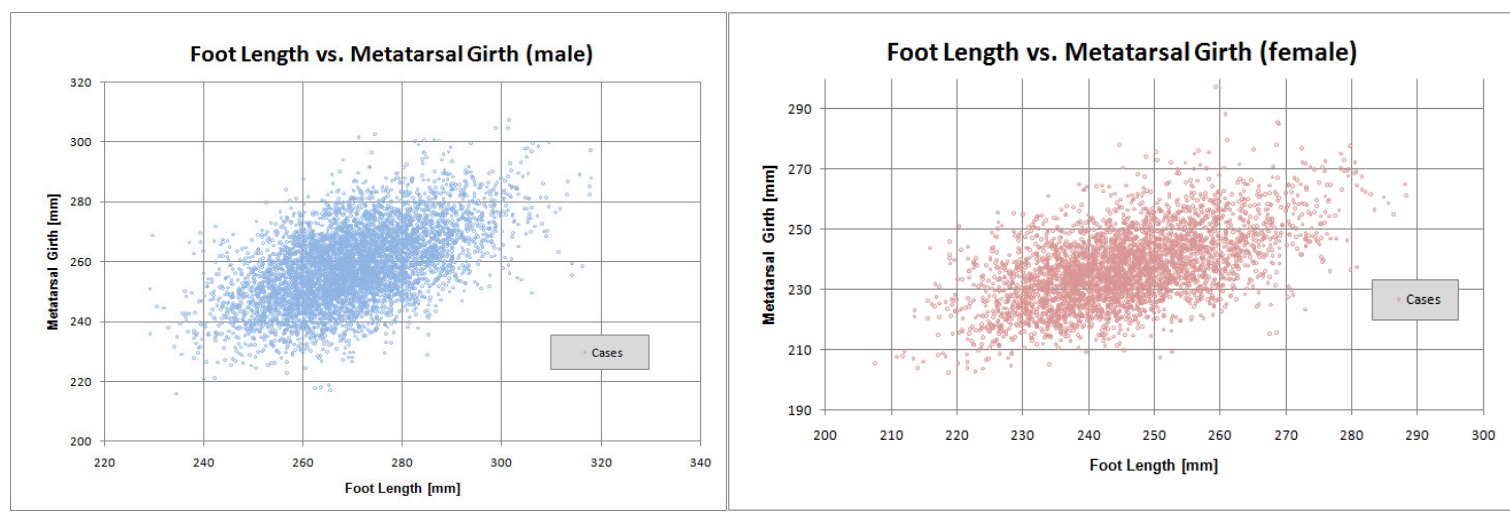

Fig. 8. Foot length vs. foot metatarsal girth charts 


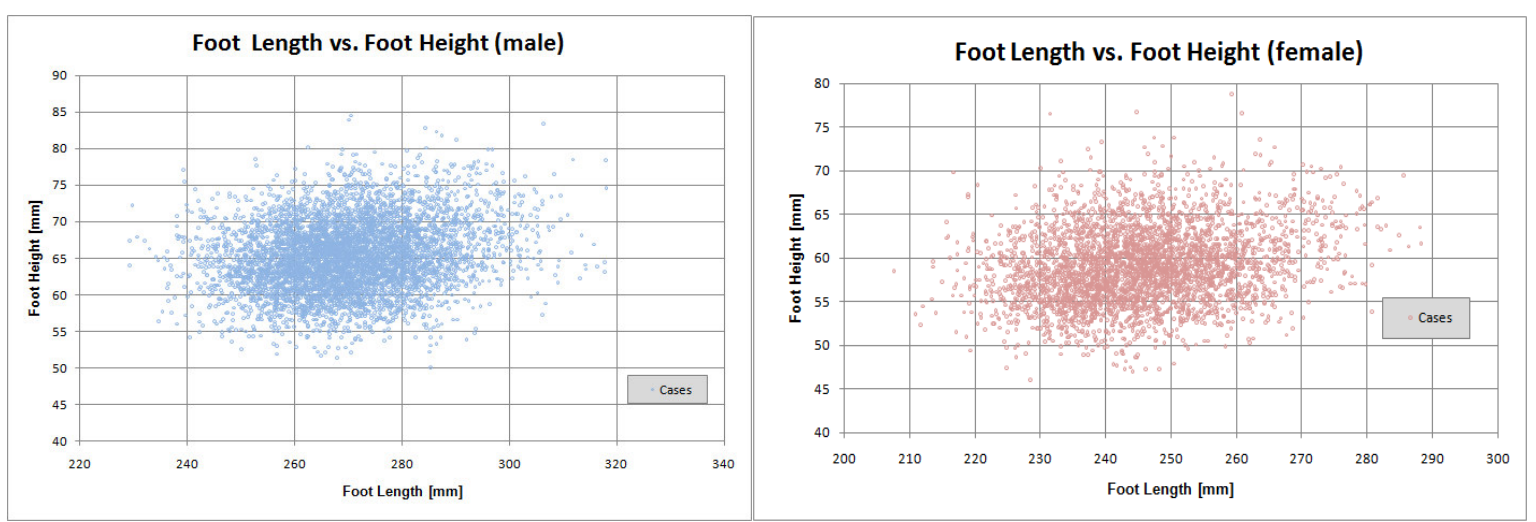

Fig. 9. Foot length vs. foot height charts

Correlations between the measured foot dimensions are displayed in Tables 1 and 2 .

Table 1. Correlations between measured foot dimensions (male)

\begin{tabular}{|c|c|c|c|c|c|c|c|c|c|}
\hline & & $\begin{array}{c}\text { Eu } \\
\text { Shoe } \\
\text { Size }\end{array}$ & $\begin{array}{l}\text { Foot } \\
\text { Legth }\end{array}$ & $\begin{array}{l}\text { Foot } \\
\text { Width }\end{array}$ & $\begin{array}{l}\text { Foot } \\
\text { Height }\end{array}$ & $\begin{array}{c}\text { Metatarsal } \\
\text { Girth }\end{array}$ & $\begin{array}{l}\text { Heel } \\
\text { Girth }\end{array}$ & $\begin{array}{l}\text { Instep } \\
\text { Girth }\end{array}$ & $\begin{array}{l}\text { Heel } \\
\text { Width }\end{array}$ \\
\hline Eu Shoe Size & Correlation & 1 &, $989^{* *}$ &, $544^{* *}$ & ,204 &, $546^{\star *}$ &, $767^{* *}$ &, $533^{* *}$ &, $550^{* *}$ \\
\hline Foot Legth & Correlation &, $989^{* *}$ & 1 &, $551^{* *}$ & ,207 &, $553^{* *}$ &, $776^{* *}$ &, $539^{* *}$ &, $557^{\star *}$ \\
\hline Foot Width & Correlation &, $544^{* *}$ &, $551^{\star *}$ & 1 &, $458^{\star *}$ &, $962^{* *}$ &, $713^{* *}$ &, $863^{* *}$ &, $619^{* *}$ \\
\hline Foot Height & Correlation &, $204^{* *}$ &, $207^{\star *}$ &, $458^{* *}$ & 1 &, $589^{* *}$ &, $571^{\star \star}$ &, $601^{* *}$ &, $399^{* *}$ \\
\hline Metatarsal Girth & Correlation &, $546^{\star *}$ &, $553^{* *}$ &, $962^{* *}$ &, $589^{* *}$ & 1 &, $776^{* *}$ &, $912^{* \star}$ &, $648^{* *}$ \\
\hline Heel Girth & Correlation &, $767^{* *}$ &, $776^{* *}$ &, $713^{* *}$ &, $571^{\star \star}$ &, $776^{* *}$ & 1 &, $802^{* *}$ &, $790^{* *}$ \\
\hline Instep Girth & Correlation &, $533^{* *}$ &, $539^{* *}$ &, $863^{* *}$ &, $601^{* *}$ &, $912^{* *}$ &, $802^{* *}$ & 1 &, $665^{* *}$ \\
\hline Heel Width & Correlation &, $550^{* *}$ &, $557^{* *}$ &, $619^{* *}$ &, $399^{* *}$ &, $648^{* *}$ &, $790^{* *}$ &, $665^{* *}$ & 1 \\
\hline
\end{tabular}

Table 2. Correlations between measured foot dimensions (female)

\begin{tabular}{|c|c|c|c|c|c|c|c|c|c|}
\hline & & $\begin{array}{c}\text { Eu } \\
\text { Shoe } \\
\text { Size }\end{array}$ & $\begin{array}{l}\text { Foot } \\
\text { Legth }\end{array}$ & $\begin{array}{l}\text { Foot } \\
\text { Width }\end{array}$ & $\begin{array}{c}\text { Foot } \\
\text { Height }\end{array}$ & $\begin{array}{c}\text { Metatarsal } \\
\text { Girth }\end{array}$ & $\begin{array}{l}\text { Heel } \\
\text { Girth }\end{array}$ & $\begin{array}{l}\text { Instep } \\
\text { Girth }\end{array}$ & $\begin{array}{l}\text { Heel } \\
\text { Width }\end{array}$ \\
\hline Eu Shoe Size & Correlation & 1 &, $988^{* *}$ &, $533^{* *}$ &, $227^{\star *}$ &, $548^{* *}$ &, $728^{* \star}$ &, $508^{* *}$ &, $519^{\star *}$ \\
\hline Foot Legth & Correlation &, $988^{* *}$ & 1 &, $541^{* *}$ &, $228^{* *}$ &, $555^{* *}$ &, $736^{\star *}$ &, $516^{\star *}$ &, $525^{\star *}$ \\
\hline Foot Width & Correlation &, $533^{* *}$ &, $541^{* *}$ & 1 &, $399^{* *}$ &, $947^{* *}$ &, $699^{* *}$ &, $845^{* *}$ &, $642^{* *}$ \\
\hline Foot Height & Correlation &, $227^{* *}$ &, $228^{* *}$ &, $399^{* *}$ & 1 &, $572^{* *}$ &, $574^{\star \star}$ &, $609^{* *}$ &, $374^{\star *}$ \\
\hline Metatarsal Girth & Correlation &, $548^{* \star}$ &, $555^{* *}$ &, $947^{* *}$ &, $572^{* \star}$ & 1 &, $783^{* *}$ &, $921^{* *}$ &, $674^{* *}$ \\
\hline Heel Girth & Correlation &, $728^{* *}$ &, $736^{* *}$ &, $699^{* *}$ &, $574^{\star *}$ &, $783^{* *}$ & 1 &, $815^{* *}$ &, $791^{* \star}$ \\
\hline Instep Girth & Correlation &, $508^{* *}$ &, $516^{* *}$ &, $845^{\star *}$ &, $609^{* *}$ &, $921^{* *}$ &, $815^{* *}$ & 1 &, $689^{* *}$ \\
\hline Heel Width & Correlation &, $519^{* *}$ &, $525^{* *}$ &, $642^{* *}$ &, $374^{* *}$ &, $674^{* *}$ &, $791^{* *}$ &, $689^{* *}$ & 1 \\
\hline
\end{tabular}




\section{Conclusions}

The Dorothy foot scanning campaign resulted in a large database of European feet with accurate 3D foot scans. The shoe producers can get valuable information about their customer's feet dimensions. They can use this information when designing lasts.

Although there have been many reports on 3D foot scanning, they comprised rather small samples. Most of the previous measurements were performed on smaller geographical areas, which didn't offer possibilities to compare foot dimensions between multiple European nations. The main conclusions of the analysis are presented in the following points.

\subsection{High foot width dispersion}

Analysis of the foot measurements shows high variability of foot width within length classes. Only a few shoe producers have been producing shoes in various widths of the same model and size. Further analysis of foot width, which is not presented in details in this paper shows, that one width per size can fit well maximum $50 \%$ of the population if the shoe is designed for the average foot width. If the shoe is produced in one with only and is not designed for the average width, it can fit well a very small percentage of the population. Three widths per size have to be used to fit well $95 \%$ of the population.

\subsection{High foot height dispersion}

Even more surprising than foot width variability is foot height variability. Foot height standard deviations are very similar to foot width deviations in all length classes. Considering the fact that average foot width is higher than average foot height, dispersion of foot height is even larger than dispersion of foot width. This means that shoes have to be designed to fit very different feet regarding the feet height. Shoe producers have been aware of this fact in the past. They have been producing shoes with laces of elastic bands which have the possibility to adapt to different heights of feet. They were probably not aware of such a high dispersion of foot height.

\subsection{Low foot width-height and foot length-height correlations}

Another interesting finding about the foot height is a low correlation between foot width and foot height. This means that a wide foot is not necessarily also a high foot, or the opposite, a narrow foot is not necessarily also a low foot. This fact has to be considered when designing multi width lasts. So far multi width lasts have been scaled by the same factor in width and height, which doesn't make sense according to the results of this study.

A very low correlation between foot length and foot height is also noticeable in this analysis.

All the findings regarding the foot height show that foot height should be seriously considered when designing shoe lasts.

Additional analyses, which are not presented in this paper, have been performed and have resulted in additional conclusions, but cannot be presented due to commercial interests of involved companies.

1. Oommen A, Mainker A, Oommen T. A Study of the Correlation Between Hand Length And Foot Length In Humans. J Anat Soc. India 2005: 54:1-9.

2. Goonetilleke, R. S., Luximon, A., and Tsui, K.-L. (2000). The Quality of Footwear Fit: What we know, don't know and should know. Proceedings of the Human Factors and Ergonomics Society Conference, 2000, San Diego, CA. July 29- August 4, 2000. Volume 2, pp. 515-518

3. Anil, A. and Peker, T. (1997). An examination of the relationship between foot length, foot breath, ball girth, height and weight of Turkish university students aged between 17 and 25 . Anthropol Anz. 1997 Mar; 55 (1):79-87

4. Goonetilleke, R. S. (2003) Designing footwear: back to basics in an effort to design for people 7th Southeast Asian Ergonomics Society (SEAES) and 4th Malaysian Ergonomics Conference (SEAMEC). Universiti Malaysia Sarawak, Kuching, Malaysia, 19-22 May 2003. pp. 25-31.

5. Olivato P., Morricone M., Fubini E., Re A. (2007): Foot Digitalization for Last Design and Individual Awareness of Personal Foot Characteristics. HCl (12) 2007: 949-958

6. Wunderlich, R.E., Cavanagh, P.R. (1999): External foot shape differences between males and females and among races. 23rd Annual Meeting of the American Society of Biomechanics, University of Pittsburgh, October 21-23, 1999.

7. C. P. Witana, J. Feng and R. S. Goonetilleke. Dimensional differences for evaluating the quality of footwear fit, Ergonomics, 40 (12):1301-1317, 2004.

8. A. Anil, T. Peker, H. B. Turgut, and S. C. Ulukent. An examination of the relationship between foot length, foot breath, ball girth, height and weight of turkish university students aged between 17 and 25. Anthropologischer Anzeiger; Bericht Uber Die Biologisch - Anthropologische Literatur, 55 (1):79--87, 31997. 